\title{
Some theoretical and practical difficulties in neonatal feeding
}

\author{
By F. E. Hytten, Obstetric Medicine Research Unit (Medical Research Council), \\ Midwifery Department, Foresterhill, Aberdeen
}

\begin{abstract}
Nearly all paediatric textbooks give considerable space to expositions of the superiority of breast feeding over bottle feeding; some even go so far as to claim that breast feeding has all the advantages and no important disadvantages. If this is really so, it seems curious that a constant stream of propaganda on behalf of breast feeding should require to be directed by public-health and other medical authorities at those who should know best, the mothers themselves. The fact is that, despite all that has been claimed for it, breast feeding is steadily losing ground; more and more mothers are feeding their babies on breast-milk substitutes. It is by no means easy to find out why this should be so, but there seems no doubt, from the experience of my colleagues and myself in Aberdeen, that many mothers honestly believe breast feeding to involve considerable dangers and defects. It is of some importance to determine whether such beliefs are illusory or otherwise.
\end{abstract}

\section{The historical background}

During the second half of the nineteenth century increasing concern was felt about the tremendously high infant mortality. In many industrial towns one baby out of every four died in its ist year. There is little information about the state of infant feeding more than roo years ago, but it was considered, no doubt correctly, that the mortality was particularly high among artificially fed babies. The science of bacteriology was in its infancy and standards of hygiene were low. Furthermore, most of the breast-milk substitutes were extremely inadequate from the nutritional point of view; Morse (1935), reminiscing on 40 years of infant feeding, stated that 'Most babies were fed on proprietary foods, a considerable proportion of which contained no milk and were mixed with water. Very few physicians had any idea what the mixtures contained, or would have understood, if they knew'. After the beginning of the present century, elaborate attempts were made to mimic the chemical composition of breast milk, but up to the time of the First World War at least, artificial feeding remained a fairly expensive, difficult and dangerous art.

Moral doubts were added to the practical considerations: one witness to the Interdepartmental Committee on Physical Deterioration (1904) went so far as to suggest that it would be wrong for the community to provide good cheap cow's milk for infant feeding, because 'One does not want, as it were, to provide an easy way for mothers to avoid feeding children, because mother's milk is the food'. On the other hand, Robert Hutchison, the famous paediatrician, testifying before the same Committee, said that 'It would be unfair to say that the average mother at present refuses to suckle her own child; she is unable to do so in quite a large 
number of cases'. But the feeling of the times was against such a reasonable view, and sufficient supplies of cheap, safe cow's milk were not provided for many years.

The propaganda in favour of breast feeding was undoubtedly justified by the circumstances which prevailed at the time, but like all propaganda it appealed to the emotions, and paid little regard to the scientific 'duty of doubt'. Bottle feeding was indicted as almost criminal selfishness, and the real or alleged benefits of breast feeding were not qualified in any way. Though the baby was the main beneficiary, it was claimed that the breast-feeding mother derived physical and psychological advantages.

The breast-feeding campaign has proceeded on these lines for more than half a century, and even now, in this country at least, there seem to be relatively few medical authorities who doubt whether it is necessary or sound. At the same time, however, the manufacturers of baby foods have spent at least as much effort advertising their wares; though this advertising is by no means disinterested, the plentiful pictures of bonny babies in the advertisements have no doubt had a powerful influence on the minds of the public. The breast-feeding campaign in recent years has at least shown restraint in seldom attacking specific proprietary foods; conversely many manufacturers throw sops to Cerberus by intimating, in small print, that 'Mother's milk is best, but ......'

It is not known whether the breast feeding campaign in its early stages succeeded in lowering the incidence of artificial feeding, but there is no doubt that during the past two or three decades artificial feeding has steadily gained popularity among mothers. Exact numerical data are scarce, but such surveys as have been made (e.g. that of Ross \& Herdan, 195I) confirm the trend away from breast feeding. Infant mortality has been falling steadily since the beginning of the century and is still falling. Fig. I gives data from Bristol and from Aberdeen which show that in both cities the fall in the breast-feeding rate since 1929 has been closely paralleled by the fall in the infant mortality rate. It is not, of course, suggested that there is a causal relationship, but the fact is clear that the appeal to the safety of breast feeding, which was so cogent $5^{\circ}$ years ago, is no longer easy to sustain.

\section{Some disadvantages of breast feeding}

The fact that an increasing proportion of mothers fails to breast feed in defiance of medical opinion suggests that breast feeding may not be so simple, safe and satisfactory as has been claimed. The well-known breast-feeding difficulties of mastitis and sore and cracked nipples have been adequately discussed elsewhere (Gunther, 1945, 1956). My own investigations (Hytten, 1954a,b) into the yield and composition of breast milk led me to the conclusion that about one-third of all mothers are unable to produce sufficient milk for the nourishment of the growing baby according to the best modern criteria; this conclusion is not so surprising when it is realized that the ability of a mother to lactate has probably never been a necessity for the survival of her child, so that little or no natural selection for lactational ability has occurred. 


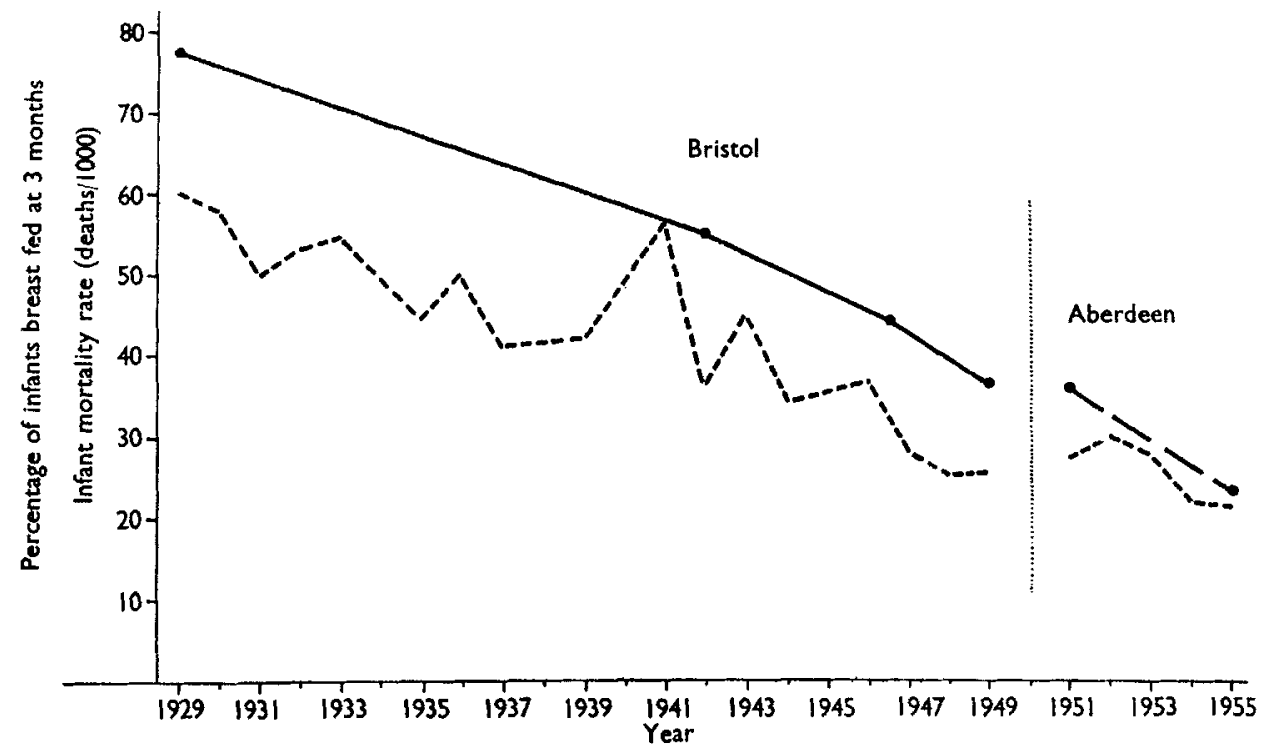

Fig. I. Percentage of infants breast fed at 3 months contrasted with the infant mortality rate between 1929 and 1949 in Bristol and $195 \mathrm{I}$ and 1955 in Aberdeen. -0 , breast-fed infants; - - infant mortality rate.

(The Bristol breast-feeding data are from Ross \& Herdan (195I), the Aberdeen data from Hytten \& Thomson (1955) and Yorston \& Hytten, unpublished).

In the remainder of this paper I wish to discuss the burden accepted by the breast-feeding mother who has no obvious anatomical or functional disability, and whose baby is healthy and thriving. Probably not more than half of all mothers who embark on breast feeding fall into this favoured category but, even for them, the cost is by no means inconsiderable.

\section{The metabolic cost}

It is generally agreed that a thriving baby requires daily some I 10-1 $20 \mathrm{Cal} / \mathrm{kg}$ body-weight, so that an average baby growing from about $3^{\frac{1}{2}} \mathrm{~kg}$ at birth to $6 \mathrm{~kg}$ at 3 months will be getting from about 400 to 700 Cal. daily from its mother's milk. The efficiency of human milk production is still in doubt; the recent report by the Food and Agriculture Organization of the United Nations: Committee on Calorie Requirements (1957) suggests $60 \%$, but unpublished information from this centre suggests that it may be a little higher, about $70 \%$. That is to say, for every 60 or 70 Cal. secreted as milk the mother must utilize $100 \mathrm{Cal}$. The lactating woman must therefore expend, in addition to her ordinary energy output, approximately 600 Cal. daily at the beginning of lactation, rising to about $\mathrm{I}$ I00 Cal. by the end of the $3 \mathrm{rd}$ month. According to the FAO report, the daily calorie requirement of an average woman engaged in general household duties is $2300 \mathrm{Cal}$., so that the average lactating woman will require more than $3000 \mathrm{Cal}$. daily; for a particularly busy woman with two or three children to care for, and no domestic assistance, the requirements may be greater. 
It is possible that the theoretical daily energy expenditure during lactation does not need to be met in full and on a day-to-day basis from the diet, since the mother tends to store nutrients during pregnancy which may be drawn during lactation. In Aberdeen, the average primipara gains about $27 \mathrm{lb}$. ( $12 \cdot 3 \mathrm{~kg}$ ) weight during pregnancy; Io days after delivery when she may be expected to have lost all her excess water and when her uterus has involuted, she has lost only I $8 \mathrm{lb} .(8 \cdot 2 \mathrm{~kg})$ of the 27. Some of the remaining $9 \mathrm{lb}$. will consist of breast tissue but it is probable that much of this gain represents stores for use during lactation. In a recent follow-up study of mothers who left hospital breast feeding (Hytten, Yorston \& Thomson, I958) it was found that at the end of 3 months, thirty-eight who stopped breast feeding within 3 weeks lost an average of only $3 \mathrm{lb}$. compared to an average loss of $6 \mathrm{lb}$. for thirty-eight who breast fed for at least ro weeks. If the average woman loses about $\frac{1}{2} \mathrm{lb}$. body-weight during each week of lactation this will represent a substantial contribution to the caloric cost of breast feeding. Calculated from Best's (1954) figure for the calorie value of body-weight lost (6400 Cal./kg) the contribution amounts to almost $200 \mathrm{Cal}$. daily; if these stores are primarily fat then the contribution may be higher. This calculation involves several assumptions but it indicates approximately the average daily subsidy which might be expected from nutrients stored during pregnancy. There are, of course, wide individual variations; about $17 \%$ of women have a net weight gain of under $2 \mathrm{lb}$. during pregnancy and therefore presumably have negligible stores for use during lactation, and about $24 \%$ gain more than $14 \mathrm{lb}$. net (Thomson \& Billewicz, unpublished).

After deducting a subsidy of $200 \mathrm{Cal}$. daily, the average requirements for lactation are still nearly $3000 \mathrm{Cal}$. Very few women are accustomed to a diet of this size even during pregnancy when their appetite is often greater than ever before. The average daily calorie intake of healthy pregnant women in Aberdeen is of the order of $2400 \mathrm{Cal}$. (Thomson, unpublished). Our patients seldom report a noticeable increase of appetite during lactation above that experienced during pregnancy; indeed many say that appetite decreases because they are tired and harassed and lack the feeling of well-being commonly experienced during pregnancy. Weighed-diet surveys we have made on eleven women in the 2 nd and 3 rd months of lactation help to confirm that the calorie intake is not greatly increased; their mean calorie intake was about $2600 \mathrm{Cal}$. daily, with a range from 2250 to 3000.

We do not know to what extent lactation in women may be prejudiced by inadequate diet. Certainly in cows there is a pronounced effect, but bovine lactation has become so specialized by breeding that it bears little relationship to the requirements of the calf, and a comparison with man is scarcely valid. Some reports from European prisoner-of-war camps and famine areas during the last war have suggested that at least some women in advanced stages of malnutrition were able to lactate (e.g. those of Antonov, I947; Smith, I947; Abels, 1949), but we have no quantitative information about the effect on lactation of undernutrition of any degree. Lactation can certainly be kept going for a time when the diet is inadequate, presumably by the breakdown of body tissues, but clearly there must be a limit to this; it seems very unlikely that undernutrition could progress to the stage of marked 
muscle wasting while lactation remained completely unimpaired. Even if adequate lactation can be maintained by some undernourished women, it is difficult to see how it can be achieved without serious impairment of health.

Any suggestion that human lactation can be improved to a significant extent by increasing or improving the maternal diet is at present entirely speculative. The women we have studied certainly have no obvious reason to restrict their diets, and it is difficult to sustain the hypothesis that they are seriously undernourished or malnourished. Our data do not show any obvious correlation between diet and milk output or composition (Hytten, I954b).

\section{The cost in well-being}

Taylor, Buskirk, Brožek, Anderson \& Grande (1957) have shown that there is a slight decline in the capacity for muscular work as body-weight is lost, with a rapid deterioration when the loss exceeds about 10\%. A loss of $10 \%$ would represent the loss of about $\times 2 \mathrm{lb}$. in our average mother, over and above what she may have stored during pregnancy, and losses of this magnitude are not common. Nevertheless the most common complaint of the breast-feeding mother is of general fatigue. It is often associated with backache or headache, sometimes with persistent minor infections such as boils or styes. The general impression conveyed is one of impaired vitality and well-being. For many, if not most, mothers the care of a baby in the first few months represents the most constant work and the longest hours in her experience. Unless she lowers her domestic standards, and very few are willing to do it, her ordinary work is not diminished: she still has the cleaning and shopping to do, meals to prepare, and other members of the family to care for. Now, in addition, she has the tyranny of a small baby demanding attention every few hours and, since she is breast feeding, this responsibility cannot be delegated. She spends a considerable proportion of each day feeding and caring for it, and restless nights anticipating it crying and feeding it when it does. For the first few weeks she can seldom depend on more than 4 hours' continuous sleep.

Amongst primiparae, whom we have particularly studied, fatigue is most prevalent among the older women, especially as they tend to persist longest with breast feeding. Increasing age, by itself, might be expected to increase the tendency to fatigue but the situation is more complex. Most women having a first baby at an older age are in the upper social classes and have high standards of domestic and infant care and live independently in relatively large houses. Few of them have more than a little part-time paid help. By contrast, a high proportion of 'working-class' women, who are usually younger when the first baby arrives, live with relatives, or in small houses where expenditure of energy can be minimized. This problem of obligatory activity during lactation may be of great importance. In a recent follow-up study of 100 breast-feeding primiparae, the only two who experienced no difficulty whatsoever during the first 3 months of breast feeding lived with their mothers and were relieved of all domestic responsibility apart from that pertaining to the immediate care of the baby. 


\section{The cost in peace of mind}

Maternal fatigue is accentuated by worry, and worry is more characteristic of the breast-feeding than of the bottle-feeding mother. The woman who has recently had a baby, particularly if she is breast feeding, frequently is less stable emotionally than usual and lacks self-confidence (Naish, I948), often expressed as doubts about her ability to produce enough milk. Many breast-fed babies cry excessively even when they are gaining weight satisfactorily and are thriving in other respects. The baby may be getting enough milk but it is difficult to convince the mother, persuaded by her sleepless husband and plausible friends, that it is not crying because of hunger. The bottle is a safe and dependable refuge; and the fact is that the baby often stops crying when bottle feeding is begun (Yorston \& Hytten, 1957). It may be that the teaching of mothercraft and the wide dissemination of 'scientific' principles of infant feeding have greatly enhanced the tendency of mothers to doubt their own capacity. Fifty years ago few mothers ever judged the feeding of their babies in terms of quantities of milk, and it must surely be a modern phenomenon of a scientific age for a mother to choose the bottle, as so many do, so that she can 'see what the baby is getting'.

Another difficulty under this heading which is peculiar to breast feeding, and probably only to breast feeding during the last generation or two, is the current need for privacy while suckling. Fifty or one hundred years ago breast feeding in public was probably common and therefore unlikely to cause embarrassment. Today it is nearly always considered essential to breast feed in privacy. Even in their own homes, many mothers will retire, if necessary into a cold room in winter, to avoid the embarrassment of feeding in the family circle.

\section{Conclusion}

The modern woman who chooses to breast feed has much against her. She needs to eat much more food than usual or she will lose weight excessively, and she is liable to feel more tired and anxious than her bottle-feeding sister. It may at first sight seem curious that a natural function such as breast feeding should be attended by so many handicaps, but these defects are a product of the environment rather than of breast feeding itself. The fault may lie with modern civilization. The woman in a less sophisticated society, living under the 'joint family' system, is able to concentrate all her time on the baby. Such domestic chores as there are can be carried by grandmother and other members of the family group, so that her energy demands are much reduced. She has no timetable of meals and shopping which prevents her from resting when she feels inclined, and she knows only one type of feeding and so avoids any conflict of choice. It probably never occurs to anyone in such a society to wonder how much the baby is getting. Though this state of affairs favours breast feeding, it is not, of course, ideal; in such societies the infant mortality rate is invariably very high, similar to the rate in our civilization half a century ago.

$I$ have not intended to give the impression that breast feeding is a poor alternative to the bottle. Many women prefer this unique experience in spite of its drawbacks 
and nothing could be more simple or satisfactory than breast feeding which is going well. What must be faced is that there is a considerable chance that it will not go well and, if a mother is having difficulty with breast feeding or is unwilling to maintain it, it is more practical and better for both physical and mental health that she should be carefully educated in how to bottle feed properly than cajoled into persisting with breast feeding.

\section{REFERENCES}

Abels, J. (r949). Brit. med. F. i, 154.

Antonov, A. N. (1947). F. Pediat. 30, 250.

Best, W. R. (1954). F. Lab. clin. Med. 44, 768.

Food and Agriculture Organization of the United Nations: Committee on Calorie Requirements (1957). FAO nutr. Stud. no. 15.

Gunther, M. (1945). Lancet, 249, 590.

Gunther, M. (1956). Lancet, 270, i75.

Hytten, F. E. (1954a). Brit. med. F. i, 249.

Hytten, F. E. (1 954b). Brit. med. F. ii, 844 .

Hytten, F. E. \& Thomson, A. M. (1955). Brit. med. F. ii, 232.

Hytten, F. E., Yorston, J. C. \& Thomson, A. M. (1958). Brit. med. F. i, 3 Io.

Interdepartmental Committee on Physical Deterioration (1904). Report of the Interdepartmental Committee on Physical Deterioration. [Cd. 2210]. London: H.M. Stationery Office.

Morse, J. L. (I935). F. Pediat. 7, 303.

Naish, F. C. (1948). Breast Feeding. London: Oxford University Press.

Ross, A. I. \& Herdan, G. (1951). Lancet, 260, 630 .

Smith, C. A. (1947). Y. Pediat. 30, 229.

Taylor, H. L., Buskirk, E. R., Brožek, J., Anderson, J. T. \& Grande, F. (1957). Y. appl. Physiol. ro, $42 \mathrm{I}$.

Yorston, J. C. \& Hytten, F. E. (1957). Proc. Nutr. Soc. I6, vi.

\section{The nutrition of young animals}

\section{By T. R. Preston, Rowett Research Institute, Bucksburn, Aberdeenshire}

In this paper I shall consider nutritional aspects of problems encountered in the rearing of calves and pigs under normal farm practice. Apart from man, these are the only mammals commonly reared both artificially and naturally and also they afford interesting examples of two widely different physiological types, namely ruminants and simple-stomached animals.

\section{Natural rearing}

The usual method of rearing pigs is to let the sow suckle them until they are 8 weeks old. A sow's milk yield begins to decline about the $3^{\text {rd }}$ or $4^{\text {th }}$ week of the $7^{\frac{1}{2}}$ weeks' lactation (Gill \& Thomson, 1956; Lodge, 1957), and to enable the young to attain their maximum rate of growth it is usual to provide ad lib. supplementary feeding in the form of a dry meal. The major problem in natural rearing is anaemia which tends to occur only when the piglets are raised indoors or on concrete. The pig is born with low reserves of iron (Venn, McCance \& Widdowson, 1947) and there 